\title{
ОСОБЕННОСТИ ПРАВОВОЙ ПРИРОДЫ БАЗ ДАННЫХ, ФОРМИРУЕМЫХ И ИСПОЛЬЗУЕМЫХ В СФЕРЕ ГОСУДАРСТВЕННОГО И МУНИЦИПАЛЬНОГО УПРАВЛЕНИЯ
}

\begin{abstract}
Аннотация. В современных условиях развития информационного общества и формирования государственной информационной политики базы данных являются важнейшим средством в разрешении проблемы упорядочения информационных ресурсов государства. Широкое использование электронных массивов информации в деятельности органов публичной власти подтверждает необходимость и важность выделения таких баз данных в качестве отдельного вида и установления для них особого правового режима. Однако изучение правовой природы баз данных и проблем правового регулирования в отношении данного объекта права до настоящего времени проводилось преимущественно в рамках науки гражданского права. Поэтому целью данной работы является исследование правовой природы публичных баз данных как объекта информационных правоотношений комплексного характера. Методологическую основу работы составляют общенаучные и специальные методы познания: моделирование и сравнение, анализ, дедукция и индукция, логический, формально-юридический и интерпретационный методы исследования. Впервые на уровне научной публикации автором выделены признаки и особенности правовой природы баз данных, формируемых и используемых в срере государственного и муниципального управления. На основе анализа категорий "публичная власть» и «публичный интерес» автор приходит к выводу, что общезначимость публичной деятельности является существенным моментом публичной власти и сущностью публичности как характеризующего признака публичных баз данных.
\end{abstract}

Ключевые слова: база данных, информационный ресурс, правовое регулирование, государственное управление, публичная власть, публичный интерес, публичность, достоверность, информация, государственные услуги.

Abstract. In the context of the modern conditions of development of the information society and the formation of information policy, databases are the most important instrument of solving the problem of the state's information resources harmonization. The widespread use of electronic information arrays in the work of public authorities proves the necessity and the importance of distinguishing such databases as an independent type, and establishing a special legal regime for them. But so far, the study of the legal nature of databases and the problems of their legal regulation has been carried out within the civil law science. Therefore, the purpose of this research is to study the legal nature of public databases as an object of information legal relations of a complex character. The research methodology is based on general scientific and special methods of cognition: modeling and comparison, analysis, deduction and induction, the logical, formal-legal and interpretation research methods. The author reveals the features and the peculiarities of the legal nature of databases, which are formed and applied in the sphere of state and municipal administration. On the base of the analysis of the categories "public authority" and "public interest", the author concludes that the general significance of public activity is an essential aspect of public authority and the essence of publicity as a characterizing feature of public databases.

Key words: publicity, public interest, public authority, state administration, legal regulation, information resource, database, authenticity, information, state services.

$\mathrm{B}$ ажнейшие преобразования в деятельности органов государственной власти и органов местного самоуправления в настоящее время связаны с реализацией мероприятий по упорядо- чению значительных массивов информации, необходимых для принятия эффективных управленческих решений и обеспечения взаимодействия названных органов публичной власти с граждана- 
ми и организациями. Такая информация приобретает качество жизненно важного информационного ресурса в сфере государственного управления.

Как отмечает Н. Н. Ковалева, без государственной информации на сегодняшний день «невозможно обеспечить эффективное взаимодействие государства и гражданского общества, поддерживать непрерывный управленческий процесс» [4, с. 110]. Анализируя понятие и структуру государственного информационного ресурса, она вводит понятие публичный информационный ресурс, понимая под ним сведения, сообщения, данные, в том числе традиционные и электронные документы, формируемые государственными и муниципальными органами [4, с. 108]. Публичные информационные ресурсы становятся важнейшими источниками получения юридически значимой информации о деятельности государственных органов и органов местного самоуправления.

Переход государственных органов на новые методы работы объективно требует проведения оцифровки и перевода огромных массивов информации в сфере публичной власти в электронную форму, в том числе форму баз данных. Именно они служат важнейшим средством, позволяющим аккумулировать и унифицировать информационные ресурсы системы государственного и муниципального управления, создавая условия как для информационного обеспечения деятельности органов власти, исполнения государственных и муниципальных функций, организации межведомственного информационного взаимодействия, так и для оказания государственных и муниципальных услуг и предоставления гражданам доступа к необходимым им сведениям. Одним словом, информация, систематизированная в базах данных, является основой для принятия управленческих решений, реализации главных функций государственного управления.

Поскольку базы данных приобретают особое значение в деятельности органов публичной власти, это подчеркивает необходимость и важность выделения таких баз данных в качестве отдельного вида (назовем их публичные базы данных) и установления для них особого правового режима.

Приоритетным признаком правовой природы публичных баз данных является особая сфера их использования - деятельность органов государственной власти и органов местного самоуправления.

Важные общественные преобразования последнего времени, особенно связанные с развитием электронных форм деятельности государства, привели к новому осмыслению института публичной власти.

В. В. Рачинский определяет публичную власть как «институционализированную легальную социальную власть, реализующую общественные интересы определенного территориального сообщества и служащую цели сохранения и развития данного сообщества в качестве целостной системы в соответствии с господствующим в обществе мировоззрением» [5, с. 13-14]. По его мнению, публичная власть в демократических обществах выполняет функции реализации публичного интереса, консолидации общества, управления, защиты существующей системы общественных отношений (охранительная), нормотворчества, обеспечения прав и свобод человека и гражданина [5, с. 9].

Среди отмеченных функций публичной власти особое внимание следует уделить реализации публичных интересов. Этот признак в качестве определяющего рассматривается многими исследователями, занимающимися изучением концепции публичного права.

В литературе публичность интересов раскрывается через природу публичных функций либо публичных вещей [2, с. 474-484], а также публичных услуг, традиционно имеющих общезначимый или «общеобязательный» характер [6, с. 45]. Поэтому общезначимость публичной деятельности является существенным моментом публичной власти и, следовательно, сущностью публичности как характеризующего признака публичных баз данных.

Важным аспектом в понимании публичной власти является также рассмотрение форм ее организации, в качестве которых принято выделять федеральную государственную власть, государственную власть субъектов РФ и местное самоуправление.

Такой подход к пониманию публичной власти и ее рассмотрение в качестве родового, обобщающего понятия является весьма устоявшимся в юриспруденции и не вызывает особых дискуссий. Более того, в современных исследованиях отмечается уже не только интегрирующая роль публичной власти, но и доказывается принцип единства публичной власти в государстве, реализуемый на различных уровнях и объединяющий государственную власть и местное самоуправление [1, с. 23-28].

Поэтому использование в рамках данной работы категории «публичная власть» является методологической основой для рассмотрения особенностей государственных и муниципальных баз данных в единой системе. Соответственно термин «публичные базы данных» в известном смысле обозначает базы данных, формируемые в общезначимых интересах федеральными органами государственной власти, органами государственной власти субъектов РФ (государственные базы данных) и органами местного самоуправления (муниципальные базы данных) в целях их последующего использования в деятельности органов публичной власти. 


\section{Административное и муниципальное право 11 (107) 2016}

Публичный характер баз данных как информационного ресурса, прежде всего, связан с их применением для предоставления государственных и муниципальных услуг, а также для исполнения государственных и муниципальных функций, что отражает один из аспектов их функционального предназначения в деятельности органов публичной власти. Причем законодатель, устанавливая правовой режим баз данных, нередко определяет таким образом цели их создания и использования. А в некоторых случаях формирование и ведение баз данных само по себе является самостоятельной публичной услугой, порядок предоставления которой прописывается в отдельных административных регламентах.

Например, публичный характер базы данных по учету трудовых арбитров определяется ее использованием для оказания Федеральной службой по труду и занятости государственной услуги по представлению сведений о трудовых арбитрах. Результатом этой государственной услуги является направление заявителю уведомления о представлении сведений о трудовых арбитрах, содержащихся в базе данных, или об отказе в представлении таких сведений [18].

Самостоятельными государственными услугами, основанными на использовании баз данных, являются также:

- государственная услуга по предоставлению информации о гидротехнических сооружениях из Российского регистра гидротехнических сооружений и доступа к сведениям базы данных Российского регистра гидротехнических сооружений (исполнитель: Федеральное агентство водных ресурсов) [17];

- государственная услуга по предоставлению гражданам информации о детях, оставшихся без попечения родителей, из федерального банка данных о детях, оставшихся без попечения родителей (исполнитель: Минобрнауки России) [15];

- государственная услуга по предоставлению сведений об итогах оценки результативности деятельности научных организаций, подведомственных федеральным органам исполнительной власти и выполняющих научно-исследовательские, опытно-конструкторские и технологические работы гражданского назначения (исполнитель: Рособрнадзор) [16].

Еще одним из важнейших направлений государственной политики, в котором особая роль отводится базам данных, является обеспечение информационной открытости, то есть своевременного и беспрепятственного доступа к достоверной и актуальной информации о деятельности органов публичной власти.
В связи с внедрением новых стандартов и требований к открытости деятельности органов власти усиливается роль баз открытых данных, призванных обеспечить размещение информации, к которой должен быть предоставлен всеобщий доступ.

Необходимость формирования таких баз данных отмечена на сегодняшний день во многих директивных документах федеральных органов государственной власти по различным направлениям социально-экономического развития страны.

Например, в Федеральной целевой программе развития образования на 2016-2020 гг. запланирован комплексный проект «Завершение разработки мониторинга системы образования, включая создание единой интегрированной системы открытых данных», в число мероприятий которого включены работы по совершенствованию механизмов использования открытых баз данных в управлении и оценке качества образования [11].

Стратегией развития медицинской науки в Российской Федерации на период до 2025 года предусматривается полномасштабное функционирование «инновационного трансфера», в рамках которого планируется создание открытой базы данных инновационных проектов в медицинской науке [13].

В области науки и инноваций реализуется обозначенный государством приоритет по обеспечению открытого доступа исследователей и научных групп к программам грантового финансирования. В Стратегии инновационного развития Российской Федерации на период до 2020 года указывается, что высокая прозрачность процедур отбора возможна только за счет обязательной публикации максимально полной информации о поступающих на конкурсы заявках и ознакомления участников конкурса по их требованию с отзывами на заявки этих участников на получение гранта. Для обеспечения открытости процедур выделения средств на научные исследования в названном документе запланировано создание общенациональной открытой базы данных, содержащей информацию о получении исследователями и исследовательскими группами всех видов государственного финансирования из различных источников, что не только обеспечит прозрачность расходования средств, выделенных на проведение исследований по различным направлениям, но и позволит вести их детальный учет [12].

Дальнейшая реализация концепции открытых данных создаст основу для развития взаимовыгодного и эффективного сотрудничества между государством и гражданским обществом, в том числе путем разработки новых информационных сервисов (условий) для обеспечения удобства и своевременности доступа населения к достоверной информации о деятельности органов публичной власти. 
Достоверность публичных баз данных также является одним из аспектов их правовой природы, который получил соответствующее правовое оформление в ст. 3 Федерального закона 27.07.2006 № 149-Ф3 «Об информации, информационных технологий и о защите информации»[9] как принцип правового регулирования отношений в сфере информации, информационных технологий и защиты информации. Используя сведения из государственных и муниципальных баз данных, лица к ним обращающиеся должны быть уверены в их достоверности и правовой надежности. Ведь во многих случаях сведения, внесенные в такую базу данных, являются основанием возникновения прав и обязанностей участников правоотношений или подтверждают конкретные факты правовой действительности. Поэтому государство должно принять все необходимые меры, для того чтобы гарантировать своим гражданам правовую защищенность от преднамеренных или случайных нарушений их прав, связанных с недостоверностью официальной информации государства, содержащейся в базах данных в сфере государственного и муниципального управления.

Требование достоверности баз данных в сфере государственного и муниципального управления может считаться реализованным при условии постоянного пополнения и обновления базы данных для поддержания актуальности содержащейся в ней информации. Речь идет о качественной обработке информационных ресурсов с точки зрения их достаточности для решения конкретных задач пользователей и удовлетворения информационных потребностей, а также их максимального соответствия объективным образам действительности. Только своевременное обновление базы данных и поддержание ее в актуальном состоянии могут обеспечить доверительный характер содержащихся в ней сведений и возможность безусловного использования субъектами права в качестве исходных оснований для совершения юридически значимых действий.

Не менее важной категорий в познании особенностей правовой природы государственных и муниципальных баз данных является категория «публичного интереса».

Теоретические основы концепции публичного интереса в отечественной юридической науке были разработаны профессором Ю. А. Тихомировым, который рассматривает публичный интерес как «признанный государством и обеспеченный правом интерес социальной общности, удовлетворение которого служит условием и гарантией ее существования и развития» [8, с. 55]. «Это - официально признанные интересы, имеющие поддержку государства и правовую защиту» [8, с. 55]. Такой же точ- ки зрения придерживается Д. Н. Горшунов, который предлагает считать, что публичный интерес - это «признанные государством общественные интересы, выраженные в нормах права и обеспеченные принудительной силой государства» [3, с 82-83].

Позиции этих ученых основаны прежде всего на том, что публичный интерес будучи признанным государством получает обязательное выражение в нормах права. То есть публичные интересы образуют те общественные потребности, которые в настоящий момент времени в силу объективной необходимости нуждаются в обеспечении надлежащей правовой защиты, и от которых зависит реализация личностных интересов отдельного человека. В этом смысле признание государством публичного интереса и его выражение в нормах права служит гарантией устойчивого развития общества. Поэтому воплощенный в праве публичный интерес должен характеризоваться своей общественной значимостью и государственной направленностью и выступать как взаимообусловленный интерес общества и государства.

На современном этапе именно информационная сфера, являющаяся системообразующим фактором для развития общества, представляет собой площадку для проявления широкого спектра разного рода публичных интересов, без обеспечения которых невозможно удовлетворение других интересов, как личных, так и общезначимых, публичных интересов государства и общества. Поэтому публичные интересы в информационной сфере определяют содержание государственной информационной политики, а создание условий для их реализации становится стратегической задачей нашего государства.

Ведущее место среди публичных интересов в информационной сфере принадлежит интересам в области формирования и использования государственных и муниципальных баз данных. В условиях назревшей проблемы модернизации страны базы данных являются не просто источником достоверной информации. Они являются информационноресурсной основой публичной власти, необходимой для внедрения новых методов принятия управленческих решений, исполнения публичных функций и реализации современныхуправленческих подходов, построенных на активном взаимодействии между государством и гражданским обществом. Поэтому публичные интересы в создании и использовании баз данных напрямую связаны с осуществлением государством своих полномочий, направленных на удовлетворение иных социально значимых потребностей в обеспечении защищенности и устойчивого развития личности, общества и государства.

Например, принятие нормативно-правовых актов, определяющих необходимость ведения 


\section{Административное и муниципальное право 11 (107) • 2016}

единого банка данных по вопросам, касающимся оборота наркотических средств, подтверждает признание государством общественных потребностей в систематизированном учете сведений, характеризующих наркоситуацию в нашей стране, для осуществления постоянного мониторинга и своевременного реагирования в этой сфере [10]. Общее благо, на обеспечение которого направлены мероприятия государства по созданию и ведению этого банка данных, состоит в противодействии незаконному обороту наркотических средств, профилактике немедицинского потребления наркотиков, лечении и медико-социальной реабилитации больных наркоманией.

Публичный интерес в создании банка данных о детях, оставшихся без попечения родителей, заключается в обеспечении централизованного учета детей и граждан, желающих принять детей на воспитание в свои семьи. Сведения о детях, оставшихся без попечения родителей, содержащиеся в государственном банке данных, используются исключительно для оказания содействия в устройстве таких детей на воспитание в семьи граждан и оказания содействия гражданам, желающим принять детей на воспитание в свои семьи, в подборе ребенка [14]. Тем самым, признание государством этого публичного интереса и его правовое оформление является одним из важнейших средств реализации основных начал семейного законодательства, согласно которым приоритет отдается семейному воспитанию детей, заботе об их благосостоянии и развитии, защите прав и интересов несовершеннолетних и нетрудоспособных членов семьи.

Следовательно, публичные интересы при использовании государственных и муниципальных баз данных, характеризуются по меньшей мере следующими признаками:

а) они являются общественно значимыми интересами, официально признанными государством и являющимися основой для развития законодательства в области формирования и использования государственных и муниципальных баз данных;

б) содержанием публичного интереса в создании и использовании баз данных являются потребности государства в обеспечении систематизированного учета в электронной форме сведений о наиболее важных с точки зрения практики развития общественных отношений фактах и событиях человеческой деятельности, субъектах и объектах права;

в) реализация публичных интересов в создании и использовании баз данных является условием организации межведомственного информационного взаимодействия, оказания публичных услуг и исполнения публичных функций, а также предоставления гражданам и организациям доступа к официальной информации.

г) публичный интерес в создании и использовании государственных и муниципальных баз данных связан с осуществлением органами публичной власти предоставленных им полномочий, направленных на удовлетворение иных общественно значимых потребностей, находящихся под защитой государства и обеспечивающих устойчивое развитие личности, общества и государства.

Важная роль в реализации публичных интересов в сфере формирования и использования баз данных принадлежит публичному праву, так как именно публично-правовые нормы призваны наиболее эффективным образом организовать деятельность публичных структур по упорядочению социально значимых информационных ресурсов.

Как отмечает Э. В. Талапина, «несмотря на то, что информационное право - яркий пример комплексной отрасли, регулирующей общественные отношения по поводу информации и ИКТ, его публично-правовые корни очевидны. Информационное право с самого начала своего формирования позиционировалось специалистами как дочерняя отрасль публичного права» [7, с . 357].

В условиях развития информационного общества активная роль в модернизации государственного управления, по мнению Э. В. Талапиной, принадлежит информационному праву, «которому предстоит урегулировать основы электронного (цифрового) государственного управления, обновить институт права на информацию в механизме обеспечения информационной открытости, закрепить принцип транспарентности государственного управления» [7, с. 98].

Поскольку публичные интересы в области формирования и использования государственных и муниципальных баз данных непосредственно связаны с реформированием государственного управления, именно отрасль информационного права, на наш взгляд, призвана обеспечить приоритет таких интересов.

Подводя итоги, можно сделать вывод, что особенностью правовой природы баз данных, формируемых и используемых в сфере государственного и муниципального управления, является признак публичности, который определяется общественной значимостью баз данных для их использования в целях организации межведомственного информационного взаимодействия, оказания государственных и муниципальных услуг и исполнения государственных и муниципальных функций, а также предоставления гражданам и организациям доступа к достоверной информации о деятельности органов публичной власти. 
Библиография:

1. Безруков А.В. Государственная и муниципальная власть в системе единой публичной власти России / А.В. Безруков // Государственная власть и местное самоуправление. 2015. № 6. С. 23-28.

2. Винницкий А.В. Публичная собственность / А.В. Винницкий. М.: Статут, 2013. 732 с.

3. Горшунов Д.Н. Интерес в частном праве: вопросы теории / Д.Н. Горшунов. Казань, 2005. 176 с.

4. Ковалева Н.Н. Административно-правовое регулирование использования информационных технологий в государственном управлении: дис. ... д-ра юрид. наук: 12.00.14, 12.00.13 / Н.Н. Ковалева. Саратов, 2014. 366 с.

5. Рачинский В.В. Публичная власть как общеправовая категория: теоретико-прикладной аспект: автореф. дис. ... канд. юрид. наук: 12.00 .01 / В.В. Рачинский. Екатеринбург, 2003. 25 с.

6. Талапина Э.В. Государственное управление в информационном обществе (правовой аспект) / Э.В. Талапина. М., 2015. 192 c.

7. Талапина Э.В. Модернизация государственного управления в информационном обществе: информационно-правовое исследование: дис. ... д-ра юрид. наук: 12.00 .13 / Э.В. Талапина. М, 2015. 469 с.

8. Тихомиров Ю.А. Публичное право: учеб. / Ю.А. Тихомиров. М.: Изд-во БЕК, 1995. 496 с.

9. Федеральный закон от 27.07.2006 № 149-ФЗ «Об информации, информационных технологиях и о защите информации» // Рос. газ. 2006. 29 июля.

10. Постановление Правительства РФ от 23.01.2006 № 31 «0 создании, ведении и использовании единого банка данных по вопросам, касающимся оборота наркотических средств, психотропных веществ и их прекурсоров, а также противодействия их незаконному обороту» // Собр. законодательства РФ. 2006. № 5, ст. 552.

11. Постановление Правительства РФ от 23.05.2015 № 497 «О Федеральной целевой программе развития образования на 2016-2020 годы» // Собр. законодательства РФ. 2015. № 22, ст. 3232.

12. Распоряжение Правительства РФ от 08.12.2011 № 2227-р «Об утверждении Стратегии инновационного развития Российской Федерации на период до 2020 года» // Собр. законодательства РФ. 2012. № 1, ст. 216.

13. Распоряжение Правительства РФ от 28.12.2012 № 2580-р «Об утверждении Стратегии развития медицинской науки в Российской Федерации на период до 2025 года» // Собр. законодательства РФ. 2013. № 2, ст. 111.

14. Приказ Минобрнауки России от 17.02.2015 № 101 «Об утверждении Порядка формирования, ведения и использования государственного банка данных о детях, оставшихся без попечения родителей» [Электронный ресурс] // Официальный интернет-портал правовой информации http://www.pravo.gov.ru, 23.03.2015 (дата обращения 30.06.2015).

15. Приказ Минобрнауки России от 15.06.2015 № 588 «Об утверждении Административного регламента предоставления Министерством образования и науки Российской Федерации государственной услуги по предоставлению гражданам информации о детях, оставшихся без попечения родителей, из федерального банка данных о детях, оставшихся без попечения родителей, для передачи их на воспитание в семьи граждан, выдаче предварительных разрешений на усыновление (удочерение) детей в случаях, предусмотренных законодательством Российской Федерации» // Рос. газ. 2015. 3 авг.

16. Приказ Минобрнауки России от 05.10.2015 № 1106 «Об утверждении Административного регламента предоставления Федеральной службой по надзору в сфере образования и науки государственной услуги по предоставлению сведений об итогах оценки результативности деятельности научных организаций, подведомственных федеральным органам исполнительной власти, выполняющих научно-исследовательские, опытно-конструкторские и технологические работы гражданского назначения» [Электронный ресурс] // Официальный интернет-портал правовой информации http://www.pravo.gov.ru, 02.11.2015 (дата обращения 06.04.2016).

17. Приказ Минприроды России от 31.10.2012 № 358 «Об утверждении Административного регламента предоставления Федеральным агентством водных ресурсов государственной услуги по предоставлению информации о гидротехнических сооружениях из Российского регистра гидротехнических сооружений и доступа к сведениям базы данных Российского регистра гидротехнических сооружений» // Бюл. нормат. актов федеральных органов исполнительной власти. 2013. № 19.

18. Приказ Минтруда России от 24.09.2015 № 659н «Об утверждении Административного регламента предоставления Федеральной службой по труду и занятости государственной услуги по представлению сведений о трудовых арбитрах, содержащихся в базе данных по учету трудовых арбитров» [Электронный ресурс] // Официальный интернет-портал правовой информации http://www.pravo.gov.ru, 23.10.2015 (дата обращения 06.04.2016)

\section{References (transliterated):}

1. Bezrukov A.V. Gosudarstvennaya i munitsipal'naya vlast' v sisteme edinoi publichnoi vlasti Rossii / A.V. Bezrukov // Gosudarstvennaya vlast' i mestnoe samoupravlenie. 2015. № 6. S. 23-28.

2. Vinnitskii A.V. Publichnaya sobstvennost' / A.V. Vinnitskii. M.: Statut, 2013. 732 s.

3. Gorshunov D.N. Interes v chastnom prave: voprosy teorii / D.N. Gorshunov. Kazan', 2005. $176 \mathrm{s.}$

4. Kovaleva N.N. Administrativno-pravovoe regulirovanie ispol'zovaniya informatsionnykh tekhnologii v gosudarstvennom upravlenii: dis. ... d-ra yurid. nauk: 12.00.14, 12.00.13 / N.N. Kovaleva. Saratov, 2014. 366 s.

5. Rachinskii V.V. Publichnaya vlast' kak obshchepravovaya kategoriya: teoretiko-prikladnoi aspekt: avtoref. dis. ... kand. yurid. nauk: 12.00.01 / V.V. Rachinskii. Ekaterinburg, 2003. 25 s.

6. Talapina E.V. Gosudarstvennoe upravlenie v informatsionnom obshchestve (pravovoi aspekt) / E.V. Talapina. M., 2015. 192 s. 


\section{Административное и муниципальное право 11 (107) 2016}

7. Talapina E.V. Modernizatsiya gosudarstvennogo upravleniya v informatsionnom obshchestve: informatsionno-pravovoe issledovanie: dis. ... d-ra yurid. nauk: 12.00 .13 / E.V. Talapina. M, 2015. 469 s.

8. Tikhomirov Yu.A. Publichnoe pravo: ucheb. / Yu.A. Tikhomirov. M.: Izd-vo BEK, 1995. 496 s.

9. Federal'nyi zakon ot 27.07.2006 № 149-FZ «Ob informatsii, informatsionnykh tekhnologiyakh i o zashchite informatsii» // Ros. gaz. 2006. 29 iyulya.

10. Postanovlenie Pravitel'stva RF ot 23.01.2006 № 31 «O sozdanii, vedenii i ispol'zovanii edinogo banka dannykh po voprosam, kasayushchimsya oborota narkoticheskikh sredstv, psikhotropnykh veshchestv i ikh prekursorov, a takzhe protivodeistviya ikh nezakonnomu oborotu» // Sobr. zakonodatel'stva RF. 2006. № 5, st. 552.

11. Postanovlenie Pravitel'stva RF ot 23.05.2015 № 497 «O Federal'noi tselevoi programme razvitiya obrazovaniya na 20162020 gody» // Sobr. zakonodatel'stva RF. 2015. № 22, st. 3232.

12. Rasporyazhenie Pravitel'stva RF ot 08.12.2011 № 2227-r «Ob utverzhdenii Strategii innovatsionnogo razvitiya Rossiiskoi Federatsii na period do 2020 goda» // Sobr. zakonodatel'stva RF. 2012. № 1, st. 216.

13. Rasporyazhenie Pravitel'stva RF ot 28.12.2012 № 2580-r «Ob utverzhdenii Strategii razvitiya meditsinskoi nauki v Rossiiskoi Federatsii na period do 2025 goda» // Sobr. zakonodatel'stva RF. 2013. № 2, st. 111.

14. Prikaz Minobrnauki Rossii ot 17.02 .2015 № 101 «Ob utverzhdenii Poryadka formirovaniya, vedeniya i ispol'zovaniya gosudarstvennogo banka dannykh o detyakh, ostavshikhsya bez popecheniya roditelei» [Elektronnyi resurs] // Ofitsial'nyi internet-portal pravovoi informatsii http://www.pravo.gov.ru, 23.03.2015 (data obrashcheniya 30.06.2015).

15. Prikaz Minobrnauki Rossii ot 15.06 .2015 № 588 «Ob utverzhdenii Administrativnogo reglamenta predostavleniya Ministerstvom obrazovaniya i nauki Rossiiskoi Federatsii gosudarstvennoi uslugi po predostavleniyu grazhdanam informatsii o detyakh, ostavshikhsya bez popecheniya roditelei, iz federal'nogo banka dannykh o detyakh, ostavshikhsya bez popecheniya roditelei, dlya peredachi ikh na vospitanie v sem'i grazhdan, vydache predvaritel'nykh razreshenii na usynovlenie (udocherenie) detei v sluchayakh, predusmotrennykh zakonodatel'stvom Rossiiskoi Federatsii» // Ros. gaz. 2015. 3 avg.

16. Prikaz Minobrnauki Rossii ot 05.10.2015 № 1106 «Ob utverzhdenii Administrativnogo reglamenta predostavleniya Federal'noi sluzhboi po nadzoru v sfere obrazovaniya i nauki gosudarstvennoi uslugi po predostavleniyu svedenii ob itogakh otsenki rezul'tativnosti deyatel'nosti nauchnykh organizatsii, podvedomstvennykh federal'nym organam ispolnitel'noi vlasti, vypolnyayushchikh nauchno-issledovatel'skie, opytno-konstruktorskie i tekhnologicheskie raboty grazhdanskogo naznacheniya» [Elektronnyi resurs] // Ofitsial'nyi internet-portal pravovoi informatsii http://www. pravo.gov.ru, 02.11.2015 (data obrashcheniya 06.04.2016).

17. Prikaz Minprirody Rossii ot 31.10.2012 № 358 «Ob utverzhdenii Administrativnogo reglamenta predostavleniya Federal'nym agentstvom vodnykh resursov gosudarstvennoi uslugi po predostavleniyu informatsii o gidrotekhnicheskikh sooruzheniyakh iz Rossiiskogo registra gidrotekhnicheskikh sooruzhenii i dostupa k svedeniyam bazy dannykh Rossiiskogo registra gidrotekhnicheskikh sooruzhenii» // Byul. normat. aktov federal'nykh organov ispolnitel'noi vlasti. 2013. № 19.

18. Prikaz Mintruda Rossii ot 24.09.2015 № 659n «Ob utverzhdenii Administrativnogo reglamenta predostavleniya Federal'noi sluzhboi po trudu i zanyatosti gosudarstvennoi uslugi po predstavleniyu svedenii o trudovykh arbitrakh, soderzhashchikhsya v baze dannykh po uchetu trudovykh arbitrov» [Elektronnyi resurs] // Ofitsial'nyi internet-portal pravovoi informatsii http://www.pravo.gov.ru, 23.10.2015 (data obrashcheniya 06.04.2016) 